\title{
FLA-63 blocks food-deprivation-induced behavioral arousal in the mouse
}

\author{
JAMES M. MURPHY and Z. MICHAEL NAGY \\ Bowling Green State University, Bowling Green, Ohio 43403
}

\begin{abstract}
Food-deprivation-induced locomotor arousal was investigated in mice using a daily 2-h shuttle cage test. In Experiment 1, deprived mice demonstrated enhanced locomotor activity compared to ad-lib controls. The pattern of the activity over 15-min intervals showed that the locomotor arousal was partly due to an attenuation of the normal within-session activity decrease characteristic of controls. This finding suggests some inhibition of habituation processes as a result of food deprivation. The second experiment indicated an important role for norepinephrine systems in the mediation of the starvation-induced arousal, as pretreatment with the dopamine- $\beta$-hydroxylase inhibitor FLA-63 blocked locomotor arousal in food-deprived mice.
\end{abstract}

Food-deprivation-induced locomotor arousal is a well-documented state of naturally occurring behavioral arousal (Campbell, 1964; Campbell \& Misanin, 1969). Considerable evidence suggests that central catecholamine (CA) systems play a mediational role in behavioral arousal (Kety, 1970), and the available data concerning the locomotor arousal attendant to food deprivation agree with this view. For example, Campbell and Fibiger (1971) observed that d-amphetamine increased locomotor activity for rats in a dosedependent manner and that increasing food deprivation greatly potentiated the stimulatory effects of a constant dosage of amphetamine. As amphetamine acts primarily upon CA systems (Groves \& Rebec, 1976), Campbell and Fibiger (1971) speculated that the interactive effect of combined food deprivation and amphetamine on behavioral arousal was mediated by CAs.

Subsequent research supported this speculation and favored norepinephrine (NE) systems as being the most important substrate. Lesions of the medial hypothalamus eliminated the potentiation of amphetamine-induced locomotor arousal by starvation, but did not alter the ad-lib response to amphetamine as compared to sham controls (Mabry \& Campbell, 1975). However, self-starving lateral hypothalamic lesioned rats and deprived sham controls both showed the potentiated locomotor arousal response to amphetamine (Campbell \& Baez, 1974). The fact that medial lesions eliminated any starvationlinked arousal and lateral lesions did not, and that lateral lesions were found to impinge mainly upon

This research was supported by a grant from the National Institute of Child Health and Human Development (HD-09145-01) to Z. Michael Nagy. The authors gratefully acknowledge the generous donation of FLA-63 by Astra Pharmaceuticals. J.M.M. is now at Institute for Psychiatric Research, Indiana University Medical Center, Indianapolis, Indiana 46223. dopamine-containing systems, led to the contention that the locomotor arousal is mediated by NE systems. The second experiment of the present study tested this contention by blocking NE synthesis in deprived animals with the dopamine- $\beta$-hydroxylase $(\mathrm{D} \beta \mathrm{H})$ inhibitor, FLA-63.

\section{EXPERIMENT 1}

The heightened activity that follows food deprivation has been observed to vary with numerous experimental parameters, including the nature of environmental stimuli, the type of apparatus, and the age and species of the subjects (cf. Baumeister, Hawkins, \& Cromwell, 1964; Campbell, 1964; Campbell \& Misanin, 1969; Campbell, Smith, Misanin, \& Jaynes, 1966; Cornish \& Mrosovsky, 1965; Murphy \& Nagy, 1979). Most studies have used rats and have housed the animals in the test apparatus for the duration of the experiment. However, it was recently demonstrated that a reliable measurement of food-deprivationinduced behavioral arousal in the mouse could be obtained using a daily 2 -h shuttle cage test, and that this economical test was comparable to continuous monitoring in activity wheels (Murphy \& Nagy, 1979). To elaborate these findings for the purposes of the present study, the first experiment again used a 2-h shuttle cage test, but the activity scores were recorded and analyzed as a function of $15-\mathrm{min}$ intervals.

\section{Method}

Subjects. The subjects were 30 adult (100-140 days of age) Swiss-Webster mice (Mus musculus) that had been bred and raised in house. Only males were used in order to avoid variable activity levels with estrous cycle (Finger, 1961). The colony room was maintained at $24^{\circ} \pm 1^{\circ} \mathrm{C}$ and was on a normal 12-h light-dark cycle beginning at $0800 \mathrm{~h}$.

Apparatus. The activity monitoring cages measured $26.5 \times 7.7$ $\times 10.0 \mathrm{~cm}$. Grid floors were made from $1-\mathrm{mm}$-diam stainless steel rods spaced $5.0 \mathrm{~mm}$ center-to-center and extending parallel 
to the width of the cage. Photocells and red-filtered light sources were mounted $5.0 \mathrm{~cm}$ from each end outside the clear Plexiglas cages. The recording circuit was programmed such that one activity count registered when alternate photocell beams were crossed, necessitating that a mouse traverse at least the $16.5-\mathrm{cm}$ distance between photocells for each count. Shuttle cages were individually enclosed in sound-attenuated chambers. Ventilation fans provided a 75-80-dB ambient noise level, and a single 6-W incandescent ceiling light illuminated each chamber. The chambers were equipped with "fish-eye" viewers that allowed for sample observations of mice during test sessions.

Procedure. The mice were randomly selected and housed individually the day before testing began. Subsequent daily test sessions were $2 \mathrm{~h}$ in length, and activity scores were recorded and analyzed as a function of 15 -min intervals.

Neither food nor water was available during the daily 2-h sessions, but was provided ad lib in the home cages for all subjects over the first 3 test days. During testing on the 3rd day, the home cages were cleaned to insure that no food had adhered to the cages. Following the third test session, the subjects were paired according to activity levels and body weights on the first 3 days, and one subject from each pair was assigned to a control or deprived group. The 15 animals assigned as controls continued to have ad-lib food and water in the home cages for the remainder of the experiment, whereas the 15 experimental animals had water available ad lib but were deprived of food. Control and deprived groups were then tested for an additional three daily sessions. Body weights were recorded each day prior to the test sessions.

\section{Results}

Analyses of the activity scores were conducted for the 3 predeprivation and 3 postdeprivation days, the factors being group, days, and 15-min intervals. Figure 1 shows that activity decreased over the 3 predeprivation days $[\mathrm{F}(2,56)=8.79, \mathrm{p}<.005]$ and consistently decreased over intervals $[\mathrm{F}(7,196)=117.40$, $\mathrm{p}<.0005]$. With repeated testing, the mice became less active at the beginning of the test sessions, resulting in a Day by Interval interaction $[F(7,392)=3.54$, $\mathrm{p}<.0005]$. The main effect for group was not significant $[F(1,196)<1.00]$, nor did group interact with other factors, suggesting no group differences on predeprivation activity.

On the 3 postdeprivation days, a significant group effect $[F(1,28)=17.06, p<.0005]$ is evident in Figure 1 . Activity generally decreased over 15 -min intervals $[F(7,196)=32.42, p<.0005]$, but deprivation altered this pattern, resulting in Day by Interval and Group by Day by Interval interactions $[\mathrm{Fs}(7,196) \geqslant$ $4.22, \mathrm{p}<.0005$ ]. These interactions reflect the fact that food deprivation acted to diminish the normal (ad-lib) within-session decrease in activity. By the 3rd day of deprivation, the deprived mice were nearly as active at the end of the 2 -h session as they were at the beginning.

Analysis of the body weight data for the 3 postdeprivation days indicated reliable effects for group $[\mathrm{F}(1,28)=30.41, \mathrm{p}<.0005]$, day $[\mathrm{F}(2,56)=184.96$, $\mathrm{p}<.0005]$, and a Group by Day interaction $[\mathrm{F}(2,56)$ $=179.42, \mathrm{p}<.0005]$. This pattern of effects was a consequence of a marked weight loss for deprived

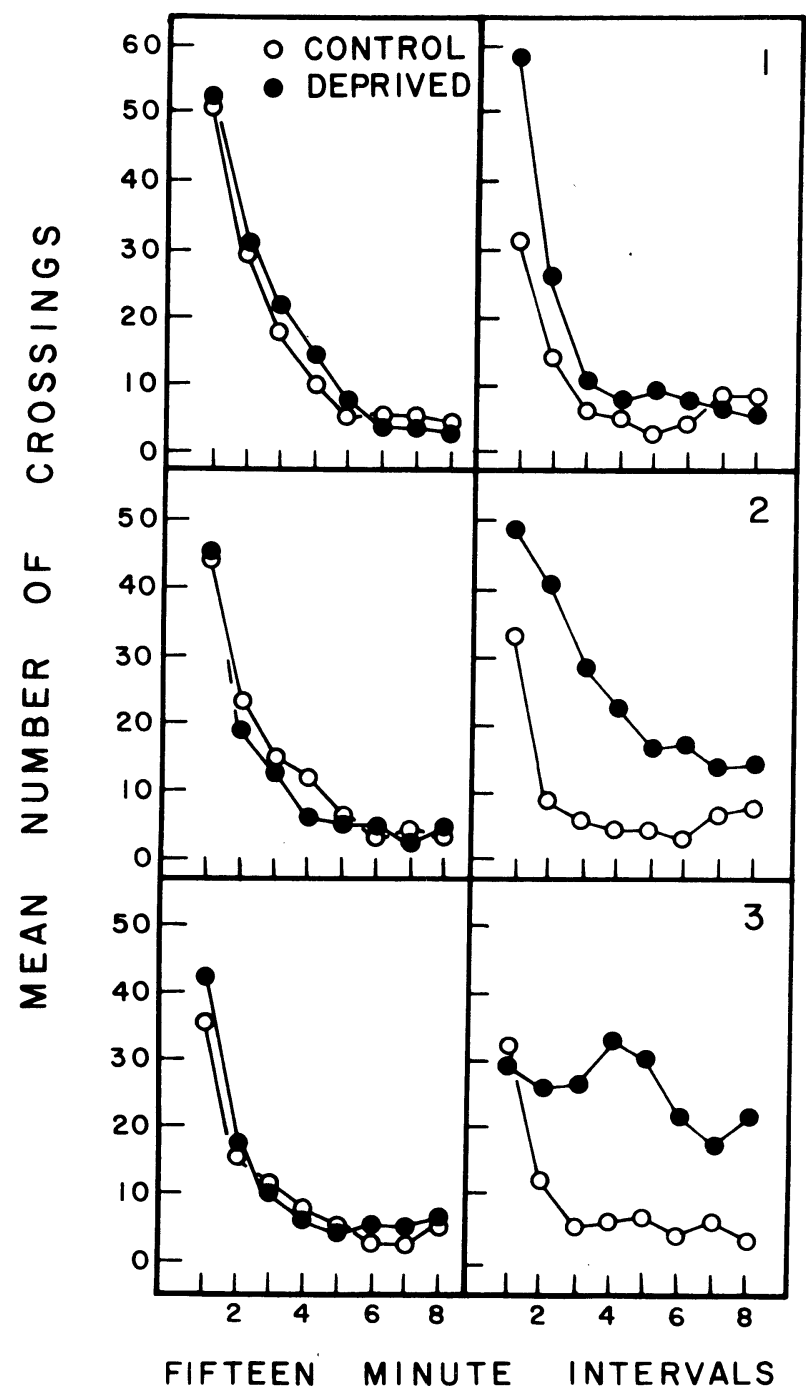

Figure 1. Mean activity scores as a function of day of testing and 15-min intervals. Both groups had ad-lib food on the 3 consecutive predeprivation days shown in the left panel. The right panel shows ad-lib controls and the 3 postdeprivation days of the deprived group.

animals over days, whereas control weights did not appreciably change.

\section{Discussion}

Enhanced activity as a result of food deprivation has been an extensively studied and often observed state of locomotor arousal, but there has been a great deal of controversy concerning the generality of the response and the underlying mechanisms which mediate the behavior (cf. Baumeister et al., 1964; Campbell, 1964; Campbell \& Misanin, 1969; Miezejeski, Lamon, Collier, \& Hamilton, 1976; Reed, 1947). The heightened activity associated with deprivation in the present experiment supports the popularly held contention that deprivation, in some way, activates sys- 
tems which mediate behavioral arousal. Although species-specificity of the behavioral arousal attendant to food deprivation has been pointed out as a potentially important factor (Campbell et al., 1966; Cornish \& Mrosovsky, 1965), the present findings are in agreement with the many studies that have used rats. A primary difference between the rat and mouse appears to be that the time course of events from commencement of deprivation through peak arousal is considerably shorter for the mouse (cf. Campbell, 1964; Murphy \& Nagy, 1979).

A practical implication of the findings is that the procedure allows for an economical, yet reliable assessment of food-deprivation-induced behavioral arousal by using a daily 2 -h test. Furthermore, a test away from the home cage circumvents the potentially important criticism of past studies that the activity could be due to an association of the test environment with food. This could occur with continuous housing in the test apparatus during baseline periods when animals are fed, and then during a subsequent deprivation phase of the experiment. Because mice in the present experiment were fed only in the home cage, the locomotor arousal response cannot be explained by an association of the test cage with food. Thus, the heightened locomotor activity is best explained as an unconditioned response arising from a deprivation-linked biological change.

\section{EXPERIMENT 2}

This experiment tested the hypothesis that NE systems mediate the locomotor arousal response to food deprivation (Campbell \& Fibiger, 1971; Mabry \& Campbell, 1975). Deprived mice were treated with the D $\beta$ H inhibitor FLA-63, thus decreasing the functional capacity of NE systems. If the starvation-arousal response is dependent upon potentiated NE synthesis and transmission, then FLA-63 treatment should eliminate or at least considerably attenuate the response.

\footnotetext{
Method

The test sequence and apparatus were the same as in Experiment 1 . A total of 60 mice were tested for three daily sessions, then matched for activity levels following the third session and assigned to four separate groups. Two groups were subsequently food deprived, whereas two groups remained ad lib. Beginning on the 4th test day (the 1st day of deprivation), one deprived and one ad-lib group received daily injections of FLA-63 $(20 \mathrm{mg} / \mathrm{kg}$, bis[4-methyl-1-homopiperazinylthiocarbonyl] disulphide; Astra Pharmaceutical) $2.5 \mathrm{~h}$ prior to testing. The FLA-63 was prepared in a fine suspension with saline and 1\% Tween 80 (polyoxyethylene sorbitan monooleate). The dosage and pretreatment parameters for FLA-63 were chosen to provide a substantial depletion of NE during the 2-h test session (cf. Flexner \& Flexner, 1976; Svensson \& Waldeck, 1969). The remaining two groups, one deprived and one ad lib, served as controls and were injected daily with the saline/Tween 80 vehicle.
}

\section{Results}

The activity results can be seen in Figure 2. Analyses of the activity scores over the 3 pretreatment and 3 posttreatment days included factors for drug (saline vs. FLA-63) and group (ad lib vs. deprived). The figure shows that the matched activity levels were nearly identical between the four conditions on the 3 pretreatment days. Activity decreased with repeated exposure to the apparatus over the pretreatment days $[\mathrm{F}(2,112)=43.65, \mathrm{p}<.0005]$ and consistently decreased over intervals within each 2 -h session $[F(7,392)=248.21, p<.0005]$, resulting in a reliable

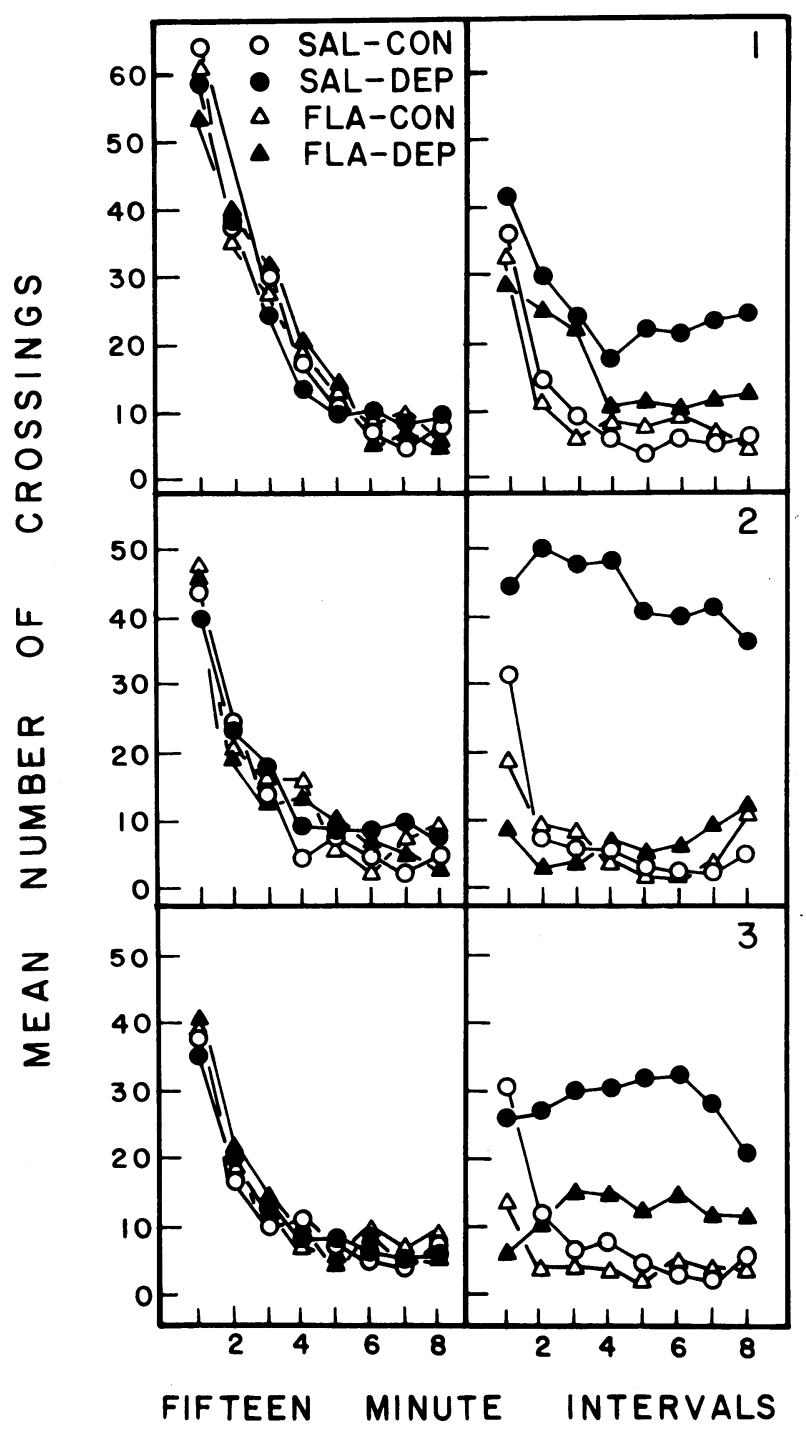

Figure 2. Mean activity scores as a function of day of testing and 15-min intervals for the four group treatment conditions. All groups had ad-lib food on the 3 consecutive predeprivation days shown in the left panel. The right panel shows the 3 postdeprivation days for food-deprived (DEP) groups and for control (CON) groups that remained ad lib throughout testing. Saline (SAL) or FLA-63 was injected on all postdeprivation days. 
Day by Interval interaction $[\mathrm{F}(14,784)=13.13$, $\mathrm{p}<.0005]$.

As in Experiment 1, analysis of the data for the posttreatment days indicated that deprivation produced a substantial increase in locomotor activity compared to ad-lib controls $[\mathrm{F}(1,56)=15.31$, $\mathrm{p}<.0005$ ], and altered the within-session activity such that the normal decrease over intervals was abated $[\mathrm{F}(7,392)=29.48, \mathrm{p}<.0005]$, yielding a Group by Interval interaction $[F(7,392)=11.31$, $\mathrm{p}<.0005$ ]. However, FLA-63 treatment considerably attenuated the heightened activity of deprived mice $[F(1,56)=9.83, p<.005]$ but had little effect on the activity of ad-lib controls, as reflected in the Drug by Group interaction $[\mathrm{F}(1,56)=6.92, \mathrm{p}<.025]$. The Drug by Group by Day and the Drug by Interval interactions, as well as higher interactions involving the interval factor, were not statistically reliable (ps $>.05$ ). Inspection of the data suggested that FLA-63 may have reduced the spontaneous activity of ad-lib controls during the first 15-min interval on the 2nd and 3rd posttreatment days, and, compared to saline controls, this difference was reliable on the 3 rd day $[\mathrm{t}(28)=3.48, \mathrm{p}<.01]$.

Deprived groups rapidly lost body weight over the 3 posttreatment days, resulting in significant main effects for group $[\mathrm{F}(1,56)=106.50, \mathrm{p}<.0005]$ and day $[F(2,112)=167.20, p<.0005]$, and a reliable interaction of these factors $[F(2,112)=101.75$, $\mathrm{p}<.0005$ ]. Individual comparisons within the interaction indicated that the weight differential between ad-lib and deprived groups was significant on all posttreatment days $[\mathrm{Fs}(1,112) \geqslant 53.77, \mathrm{p}<.0005]$. One difference from Experiment 1 was that two subjects expired on the 3rd day of deprivation, one in each of the deprived groups.

\section{Discussion}

The finding that FLA-63 treatment reduced the activity of deprived mice to near control levels provides a direct test of the contention that starvationinduced locomotor arousal is mediated by NE systems (Campbell \& Fibiger, 1971; Mabry \& Campbell, 1975), and supports the more general theoretical position that NE transmission is directly related to an organism's state of behavioral arousal (Kety, 1970; Schildkraut \& Kety, 1967). While the present findings do not eliminate the possibility that other biochemical systems are important substrates for deprivationinduced arousal, they do indicate the essential nature of NE systems.

Although the present experiment does not address whether FLA-63 exerts its effect by a peripheral or central action, previous studies suggest that central $\mathrm{NE}$ is critical to deprivation-induced behavioral arousal. For example, adrenal demedullation does not eliminate starvation-induced activity (Fibiger \&
Campbell, 1971), nor does adrenalectomy or peripheral sympathectomy eliminate the potentiation of deprivation-linked locomotor arousal by amphetamine (Simpson, 1974). Moreover, it has been demonstrated that blocking the central action of FLA-63 prevents any reduction of motility (Svensson, 1971; Svensson \& Waldeck, 1970), indicating that the systemic presence of FLA-63 does not alter the behavior. On the other hand, the systemic injection of NE, which enters the brain with great difficulty, does not counter the locomotor attenuation following FLA-63 treatment (Svensson, 1971). In agreement with the previous findings, FLA-63 in the present experiment did not decrease the spontaneous activity of ad-lib controls, except in the first interval on the 3rd posttreatment day. The latter finding may suggest some attenuation of the normal, ad-lib arousal level or perhaps a cumulative, nonspecific effect of the drug. However, the fact that FLA-63 generally did not reduce spontaneous activity but did reliably eliminate the heightened activity of deprived mice attests that any nonspecific effects of the drug are probably minimal, at least in the dosage used here.

\section{GENERAL DISCUSSION}

Food deprivation of mice in this study and previously (Murphy \& Nagy, 1979) was found to produce a precipitous decline in body weight over 3 days paralleled by a rise in locomotor activity which was several times that of ad-lib controls after 2 and 3 days. The average asymptote in body weight loss occurs on the 3rd day of deprivation (Murphy \& Nagy, 1979) and probably reflects the point where fat stores near depletion for the majority of the animals, followed by an increased utilization of cellular protein. Observation of the animals and examination of the data suggested that the highest activity levels usually occurred on the 3rd day of deprivation, and many subjects began to appear weak and lethargic around the end of the 3rd day. The pattern of these effects suggests that the progressive deprivation activates arousal systems and that activity levels continue to rise until inanition becomes evident. The second experiment suggests that the locomotor arousal response to food deprivation requires NE systems, as treatment with a D $\beta \mathrm{H}$ inhibitor FLA-63 blocked the response.

Although the most evident behavioral effect of food deprivation was an elevation of locomotor activity relative to controls, the 2 -h test procedure showed that the behavioral arousal might be due, at least in part, to an attenuation of habituation processes (cf. Miezejeski et al., 1976). This is evident from the fact that, as deprivation continued, activity levels of control and deprived groups did not differ appreciably at the beginning of the test sessions but 
that deprived groups demonstrated much less of a within-session decrease than did controls. The findings, therefore, may indicate that food deprivation has effects which include an inhibition of systems mediating habituation and, moreover, suggests that the activation of NE arousal systems could be indirect. This interpretation disagrees with numerous past studies of food deprivation in rats where the heightened activity has been viewed as reflecting a direct activation of arousal systems (Campbell, 1964; Mabry \& Campbell, 1975; Mathews \& Finger, 1966). Though this possible contradiction may be attributed to a species difference between rats and mice (cf. Baumeister et al., 1964; Campbell et al., 1966; Murphy \& Nagy, 1979), it may also be that the different procedure used in this study can account for the contradictory findings. While past studies have generally employed continuous monitoring of the activity and averaging of the activity scores over relatively long intervals, the present study tested the animals away from the home cage in a neutral environment and recorded the activity over relatively short (15-min) intervals during the 2 -h sessions. The latter procedure, obviously much more sensitive to changes in habituation processes, showed that the heightened activity of deprived animals was partly relative to the decreasing activity of controls.

In summary, the findings suggest that elevated activity associated with food deprivation may be mediated to some degree by systems which control behavioral habituation and inhibitory processes. It can only be speculated that these might be cholinergic and/or serotonergic systems, which are thought to mediate behavioral inhibitory processes and act reciprocally with NE arousal systems (cf. Carlton, 1969; Hollister, Breese, Kuhn, Cooper, \& Schanberg, 1976; Mabry \& Campbell, 1973). However, the present study demonstrates that NE systems cannot be discounted as an important pathway for the expression of the deprivation-induced behavioral arousal.

\section{REFERENCES}

Baumeister, A., Hawkins, W. F., \& Cromwell, R. L. Need states and activity level. Psychological Bulletin, 1964, 61, 438-453.

Campbell, B. A. Theory and research on the effects of water deprivation on random activity in the rat. In $\mathbf{M}$. J. Wayner (Ed.), Thirst. New York: Pergamon Press, 1964.

Campbell, B. A., \& Baez, L. A. Dissociation of arousal and regulatory behaviors following lesions of the lateral hypothalamus. Journal of Comparative and Physiological Psychology, 1974, 87, 142-149.

Campbell, B. A., \& Fibiger, H. C. Potentiation of amphetamineinduced arousal by starvation. Nature, 1971, 233, 424-425.

Campbell, B. A., \& Misanin, J. R. Basic drives. Annual Review of Psychology, 1969, 20, 57-84.
Campbell, B. A., Smith, N. F., Misanin, J. R., \& Jaynes, J. Species differences in activity during hunger and thirst. Journal of Comparative and Physiological Psychology, 1966, 61, 123-127.

Carlton, P. L. Brain-acetylcholine and inhibition. In J. T. Tapp (Ed.), Reinforcement and behavior. New York: Academic Press, 1969.

Cornish, E. R., \& Mrosovsky, N. Activity during food deprivation and satiation of six species of rodent. Animal Behaviour, $1965,13,242-248$.

Fibiger, H. C., \& Campbell, B. A. Effect of adrenal demedullation on starvation-induced behavioral arousal. Physiology \& Behavior, 1971, 6, 403-405.

Finger, F. W. Estrous activity as a function of measuring device. Journal of Comparative and Physiological Psychology, 1961, 54, 524-526.

Flexner, J. B., \& Flexner, L. B. Effect of two inhibitors of dopamine- $\beta$-hydroxylase on maturation of memory in mice. Pharmacology, Biochemistry \& Behavior, 1976, 5, 117-121.

Groves, P. M., \& ReBec, G. V. Biochemistry and behavior: Some central actions of amphetamine and antipsychotic drugs. Annual Review of Psychology, 1976, 27, 91-127.

Hollister, A. S., Breese, G. R., Kuhn, C. M., Cooper, B. R., \& SChANBERG, S. M. An inhibitory role for brain serotonincontaining systems in the locomotor effects of d-amphetamine. Journal of Pharmacology and Experimental Therapeutics, 1976, 198, 12-22.

KETY, S. S. The biogenic amines in the central nervous system: Their possible roles in arousal, emotion, and learning. In F. O. Schmitt (Ed.), The neurosciences: Second study program. New York: Rockefeller University Press, 1970.

MabRY, P. D., \& CAMPBELl, B. A. Serotonergic inhibition of catecholamine-induced behavioral arousal. Brain Research, 1973, 49, 381-391.

Mabry, P. D., \& CAmpbell, B. A. Potentiation of amphetamineinduced arousal by food deprivation: Effect of hypothalamic lesions. Physiology \& Behavior, 1975, 14, 85-88.

Mathews, S. R., JR., \& Finger, F. W. Direct observation of the rat's activity during food deprivation. Physiology \& Behavior, 1966, 1, 85-88.

Miezejeski, C. M., Lamon, S., Collier, G., \& Hamilton, L. W. Partitioning of behavioral arousal. Physiology \& Behavior, 1976, 17, 581-586.

MurPhy, J. M., \& NAGY, Z. M. Comparison of behavioral activity in two apparatus for food-deprived mice. Bulletin of the Psychonomic Society, 1979, 14, 43-45.

REED, J. D. Spontaneous activity of animals. A review of the literature since 1929. Psychological Bulletin, 1947, 44, 393-412.

Schildkraut, J. J., \& Kety, S. S. Biogenic amines and emotion. Science, 1967, 156, 21-30.

Simpson, L. L. A study of the interaction between amphetamine and food deprivation. Psychopharmacologia, 1974, 38, 279-286.

Svensson, T. H. On the role of central noradrenaline in the regulation of motor activity and body temperature in the mouse. Naunyn-Schmiedeberg's Archives of Pharmacology, 1971, 271, 111-120.

Svensson, T. H., \& W ALDECK, B. On the significance of central noradrenaline for motor activity: Experiments with a new dopamine $\beta$-hydroxylase inhibitor. European Journal of Pharmacology, 1969, 7, 278-282.

Svensson, T. H., \& WALDEck, B. On the role of brain catecholamines in motor activity: Experiments with inhibitors of synthesis and of monoamine oxidase. Psychopharmacologia, 1970, 18, 357-365.

(Received for publication April 6, 1979; revision accepted November $12,1979$. 